\title{
Fontes de conflito na Pedagogia contemporânea
}

\section{Professor emérito da Universidade de Kassel}

\section{Resumo}

O texto traz ao debate alguns aspectos elucidativos do fundo conceptual e estrutural do pensamento de Pedro Goergen relacionada ao campo triangular da ética, da política e da educação. O autor destaca os conflitos que subjazem à prática educativa e que causam tensões que dificultam o manejo dos desafios que se fazem presentes na educação atual, ponderando que tais conflitos somente perderão seu potencial perturbador se os profissionais da educação se conscientizarem da sua intromissão no espaço pedagógico. Para tanto, a Pedagogia precisa tornar-se um campo de problematização e enfrentamento das fontes desses conflitos.

Palavras-chave: Pedagogia; Formação; Conflitos pedagógicos.

\begin{abstract}
The text brings to the debate some illustrative aspects of the conceptual and structural background of Pedro Goergen's thought related to the triangular field of ethics, politics and education. The author highlights the conflicts that underlie the educational practice and cause tensions that hinder the management of the challenges that are present in the current education, considering that such conflicts only lose their disruptive potential if education professionals become aware of their intrusion into the educational space. Therefore, pedagogy must become a field of problematization and confrontation of the sources of these conflicts.
\end{abstract}

Keywords: Education; Formation; Pedagogic conflicts. 


\section{Considerações iniciais}

escolha do tema de minha contribuição tem vínculo direto com o
trabalho desenvolvido pelo colega e amigo Pedro Goergen, ao
longo de sua carreira acadêmica. Até hoje, os interesses desse filósofo da educação vêm enfocando questões relacionadas, sobretudo, ao campo triangular no qual se entrelaçam Ética, Política e Educação. Embora não me sinta capaz de honrar o amplo leque dos problemas em jogo nesse entrelaçamento, trarei ao debate alguns aspectos elucidativos quanto ao seu fundo conceptual e estrutural. O meu intuito é caracterizar neles diferentes níveis de tensão que me parecem dificultar o manejo dos desafios enfrentados hoje pelo sistema educacional. Meu diagnóstico trata, portanto, de conflitos que subjazem à prática educativa, influenciando-a de modo apenas oculto. Estou convencido de que tais conflitos somente perderão seu potencial perturbador se os profissionais da área chegarem a conscientizarse dessa sua intromissão no espaço pedagógico.

Divido meus raciocínios em duas partes. A primeira abordará conflitos conceptuais que, embora presentes nos debates teóricos da Pedagogia, pouco têm influenciado a consciência prática dos educadores profissionais. Para legitimar essa minha suspeita, eu me utilizarei de três exemplos. A segunda parte exporá tensões entre diretrizes estruturais que interferem no campo pedagógico. Por se tratar de fundos organizacionais, jurídicos e sociológicos, essas diretrizes ficam tradicionalmente mais longe da mira dos pedagogos. Devido à indiferença usual em relação a esses aspectos, acho oportuno reintroduzi-los no debate, ampliando assim o leque temático do contexto, em que Pedro Goergen tem voz ativa e respeitada. Sendo assim, meus raciocínios tomam como ponto de partida questões conceptuais intrínsecas ao debate pedagógico para chegar a aspectos aparentemente 
externos a esse campo. Eles marcam um fundo clandestino de conflitos, cujos efeitos não deveriam ser subestimados.

\section{Tensões entre diretrizes conceptuais}

O conflito conceptual mais presente nos debates pedagógicos é antigo e envolve, por um lado, a tradicional ideia de formação - defendida, desde o início do século XIX, pelo seu protagonista e então ministro prussiano Wilhelm von Humboldt - e, por outro, a visão atual que reduz a formação cada vez mais a um processo de mera instrução profissional. Seja qual for o nível em que se desenvolva o debate sobre diretrizes da educação, a referência implícita a esses dois extremos está sempre presente. É desnecessário reconstruir em detalhes esse conflito; contento-me em resumir os raciocínios mais importantes que sustentam as duas visões.

O modelo humboldtiano toma o educando como indivíduo singular, com suas peculiaridades próprias; e o foco é dirigido ao seu potencial específico com o fim de desenvolvê-lo. A tarefa da formação consiste aí em dar à pessoa as mais amplas chances de ativar esse seu potencial. E caberia, por isso, às políticas de educação providenciar condições que levem a alcançar tal objetivo. A autorrealização da pessoa, no sentido de poder fazer suas próprias opções de vida - eis a tese de Humboldt -, depende da possibilidade de o indivíduo experimentar suas forças e predisposições; algo que só se realiza quando, ao longo de sua formação, ele consegue viver as mais variadas condições sociais e institucionais. O indivíduo vê-se, assim, desafiado a se conscientizar a respeito das preferências e dos critérios éticomorais que deveriam orientar sua postura social. Esse é o sentido do projeto de "evolução cultural" do ser humano, propagado por W. v. Humboldt. (FLICKINGER, 1998, p. 414-429). Uma bela metáfora dá a entender o que Humboldt tinha em mente: não cabe ao Estado o papel do engenheiro que

Filosofia e Educação [RFE] - Volume 8, Número 2 - Campinas, SP Junho-Setembro de 2016 - ISSN 1984-9605 - p. 44-61 
constrói as vidas de seus membros segundo um plano racional premeditado; antes, pelo contrário, sua função é o trabalho do jardineiro, que, por meio do cultivo, providencia as melhores condições ambientais para "a formação máxima e mais proporcional possível das forças para um todo" (FLICKINGER, 1998, p. 414-429) ${ }^{1}$

Enquanto essa visão humboldtiana destaca a importância da formação do indivíduo, respeitando suas condições específicas, o sistema educacional contemporâneo enfatiza cada vez mais diretrizes não vinculadas às condições individuais do educando. $\mathrm{O}$ que hoje domina o cenário são reivindicações externas, que fazem do indivíduo o mero epifenômeno de uma lógica a ele alheia; lógica não imposta pela política do Estado - como se poderia imaginar -, senão pela própria sociedade civil e, mais precisamente, pelo sistema econômico que está no seu cerne. A redução da "formação" à instrução profissional resulta de demandas provenientes de um mercado de trabalho altamente diferenciado e com ramificações pouco transparentes. Indicadores dessa tendência não faltam. Lembro apenas o aumento dramático de perfis profissionais que vêm criando um mercado selvagem, por exemplo, de currículos acadêmicos do bachelor e do master. Lembro, também, a crescente dificuldade de realizar uma carreira profissional estável à base de uma determinada qualificação. O patchwork profissional vem há muito substituindo carreiras tradicionais de longo prazo e traz consigo incertezas e riscos quanto ao planejamento responsável das biografias individuais e sociais.

A assim chamada "modernização" da sociedade leva, passo a passo, à necessidade de pensar na possibilidade de desfazer o conflito entre a ideia tradicional da formação e as demandas criadas pela lógica econômica que subjaz ao mercado de trabalho. Numa primeira etapa, uma possível solução

1 Citação de W. v. Humboldt.

Filosofia e Educação [RFE] - Volume 8, Número 2 - Campinas, SP Junho-Setembro de 2016 - ISSN 1984-9605 - p. 44-61 
passaria pela exposição e pela discussão abertas dos argumentos em jogo, já que cada uma das concepções recorre a considerações que, em si racionais, não podem ser facilmente negligenciadas. No que se refere à perspectiva humboldtiana, a seu favor tem-se a defesa da ideia de liberdade individual. Esta sustenta, como fim em si, o projeto político da sociedade iluminista, empenhado em providenciar a maior liberdade possível para seus membros. Por sua vez, a racionalidade intrínseca ao atual modelo econômico legitima demandas materialmente definidas, das quais a educação também não pode esquivar-se, pois, sem os recursos materiais criados pela economia, não há como investir na educação. São duas lógicas diferentes, embora complementares, que trazem, cada uma, argumentos fortes em favor de suas reivindicações. Acredito que a solução do impasse será possível somente na busca da medida certa (no sentido de Platão), uma medida que faça jus à concatenação objetiva das duas concepções, não as vendo como alternativas de polos mutuamente excludentes. E se poderia abrir, assim, a chance de transformar a tensão aparentemente conflitante em uma constelação produtiva.

No que tange aos objetivos da educação, outra rivalidade conceptual que contribui à geração de atritos tem a ver com o tipo de postura ou hábito a ser cultivado pelos educadores em relação aos educandos. A tensão aí observada remete àquela antes discutida entre a ideia humboldtiana de formação e a instrução profissionalizante. Dá para distinguir dois extremos: aquele da postura maiêutica e aquele da utilitarista. $O$ primeiro é caracterizado pelo reconhecimento mútuo do potencial racional do educando e do educador. Aí, não há necessidade de ter a última palavra, nem a intenção de impor verdades prévias. O educando vê-se levado a participar dum processo no qual é também interlocutor, contribuindo na descoberta do conhecimento. Essa arte socrática de dialogar permite a criação endógena de 
um saber exposto sempre ao risco de ser contestado pelo argumento melhor. Abrir-se e entregar-se aos argumentos do outro interlocutor leva a que o processo educativo torne-se também uma experiência social, na qual os participantes aceitam-se mutuamente como seres racionais e conquistam, assim, a autoestima essencial ao sucesso pedagógico. Sem dúvida, a postura maiêutica aposta tudo na primazia do melhor argumento e faz do processo educativo uma aventura através do mundo da razão; o educando precisa, contudo, de ajuda para chegar a ele. E o objetivo é torná-lo capaz de movimentar-se neste mundo e escolher o modo seu de entrosamento intelectual e social. A formação tem aí o seu fim em si, podendo renunciar a qualquer diretriz vinda de fora.

Diferentemente dessa postura maiêutica, a concepção instrumental da pedagogia tem em vista um indivíduo disposto a cumprir exigências que lhe são alheias. $\mathrm{O}$ ideal dessa concepção é um sujeito disposto a submeter-se às demandas do mercado de trabalho. Uma reivindicação que não exige apenas formação profissional, senão, também, uma sua atualização contínua. Nesse caso, o indivíduo vê-se exposto ao risco permanente de trocar sua identidade profissional. Trata-se, em última instância, da "flexibilização" da pessoa, de modo que se torne capaz de adaptar-se a quaisquer transformações da lógica econômica. O caráter da pessoa vê-se, como diz Sennett (1999), "corroído" pela lógica de trabalho hoje dominante, tornando-se um meio útil meramente. Trata-se de uma constelação bem curiosa, pois aqui é a própria sociedade civil da qual o indivíduo é membro, que dele exige a disposição de submeter-se a uma lógica desinteressada nas opções e nos projetos de sua própria vida. E assim, desde que sigam a concepção instrumental dessa pedagogia, cabe às políticas de educação do Estado apenas ratificar o que a sociedade civil determina, a saber, adestrar o indivíduo para entrosar-se, sem maiores atritos, na lógica econômica. O "homem unidimensional" 
(MARCUSE, 1973) - eis a sua etiqueta. Não se tem espaço aí, obviamente, para procedimentos maiêuticos.

É claro que esses dois tipos referidos de postura ocupam dois extremos. No entanto, não há como negar que os debates entabulados na Pedagogia há algum tempo remetem, ao menos de modo implícito, a um ou a outro desses ideais do "produto" de formação. O conflito tem caráter ideológico: à tese do ideal liberal que visa a conceder ao indivíduo as melhores condições para realizar seus próprios sonhos de vida opõe-se aquela de que o maior lucro do indivíduo estaria em submeter-se à lógica econômica. A primeira opção dificilmente surte efeitos positivos a curto prazo; mas, ao que tudo indica, a lógica econômica do liberalismo, em contrapartida, não consegue garantir resultados vantajosos a longo prazo. Num certo sentido, a constelação reproduz as dúvidas da ética utilitarista quanto aos efeitos visados. Pergunta-se, então: como decidir entre a postura instrumental, que traz consigo vantagens somente a curto prazo, e a postura maiêutica cujos efeitos positivos talvez se manifestem apenas a médio ou a longo prazo? É mais aconselhável buscar o ganho imediato sem preocuparse com as consequências negativas a longo prazo, ou aceitar dificuldades imediatas para contar com ganhos posteriores?

Mais uma vez vale o proposto anteriormente para solucionar o conflito entre os objetivos da educação enquanto formação, ou então enquanto instrução profissional: em vez de encarar as posturas referidas - a maiêutica e a instrumental - como alternativas excludentes, o debate pedagógico deveria antes buscar caminhos que levassem em consideração o alcance e os limites objetivos de ambas, a fim de fazer jus ao papel indispensável de cada uma delas.

Falando ainda em termos conceptuais, quero apontar um terceiro aspecto da tensão que envenena as discussões no âmbito da Pedagogia. 
Refiro-me a uma questão metodológica, intrínseca ao conflito em torno do projeto de capacitar o educando a desenvolver seu espírito crítico. A questão não é nova; ao contrário, ela nasceu nos anos 60 do século passado, no contexto da questão quanto a quais seriam os caminhos certos da crítica das ideologias. Para respondê-la, recorro a um exemplo típico que vivi repetidamente no trabalho com jovens, exemplo não raro mas pouco considerado pelos educadores.

A fascinante experiência feita com uma nova teoria ou com pessoa extraordinária, capaz de defender com a verve devida uma determinada posição teórica, exerce, sem dúvida, sobre os jovens e mesmo sobre outros profissionais da área, uma atração comparável àquela do amor à primeira vista. Fascinado à primeira impressão, o indivíduo fica cego em relação a tudo que, operando em fundo clandestino, poderia pô-la em xeque. Como que possuído, ele defende aquilo que o fascinou contra quaisquer objeções feitas por outrem. A teoria e/ou pessoa em questão é(são) tratada(s) como se fosse $(\mathrm{m})$ propriedade privada, cuja posse passa a definir a autoconsciência do "enamorado" e que, por isso mesmo, tem de ser preservada a qualquer custo. E é justamente essa pretensa exclusividade que, no caso da teoria, faz da posição assumida uma mera ideologia cujos pressupostos tornam-se inquestionáveis. O mesmo vale para a pessoa adorada. Quem não conhece aqueles pregadores da verdade, cujo objetivo educacional em sala de aula consiste em mera doutrinação, mediante a qual buscam vender suas convicções? Desde os primeiros estágios pré-escolares até as lutas intelectuais na universidade, todos nós temos a oportunidade de observar esse desejo de afirmar verdades últimas e impô-las aos jovens, no intuito de criar partidários de uma determinada escola intelectual. Muitas vezes, a estratégia é bem-sucedida graças a um efeito como que colateral; a saber, ela parece oferecer certezas bem vistas como vantagens aparentemente 
irresistíveis diante do pluralismo desconcertante de ideias. Pois a conquista de um chão supostamente firme não facilita apenas a orientação num mundo complexo, senão traz também consigo a chance de evitar a responsabilidade por erros de decisão próprios. A ideologia seduz tanto os jovens quanto os educadores com a promessa de acabar com a crescente insegurança. Quanto mais os indivíduos - sejam eles educandos ou educadores - carecem de consciência reflexiva, tanto maior sua susceptibilidade em relação à doutrinação apodítica de ideologias. As consequências para a educação são previsíveis: à medida que a "sociedade de risco" (BECK, 2010) priva as pessoas de condições estáveis e calculáveis de vida, seu sistema de educação passa a compensar essa perda pela busca de novas certezas e referenciais considerados estáveis. A invasão de ideologias nas instituições educacionais, junto à sua resistência a qualquer sensibilidade crítica, torna-se uma estratégia mais eficiente a curto prazo frente às crescentes inseguranças sociais e culturais.

Contra a ideologização da educação como resposta à insegurança geral da sociedade de risco, o projeto oposto de manejar a situação cada vez mais precária, sobretudo para os jovens, aposta tudo na criação e no reforço do espírito crítico como objetivo do processo de formação. No cerne dessa concepção está a ideia de levar os educandos a questionarem o que se esconde por trás dos fenômenos aparentemente objetivos - trate-se de uma teoria afirmativa, de um comportamento pessoal bem-sucedido, de ações coletivas na política ou de outras manifestações. Um objetivo que, em casos extremos e mal refletidos, torna, entretanto, a atitude crítica um fim em si, ou seja, leva - contra a intenção originária - a própria pretensão crítica a desemborcar na mera ideologia. Permito-me, agora, fazer um breve excurso, no intuito de esclarecer o cerne desse problema. 
De uma ou outra maneira, a Pedagogia crítica vem desde sempre acompanhando os debates sobre os objetivos da educação. Identificada, às vezes, também como "Pedagogia dialética" (ver o título do livro de Wd. Schmied-Kowarzik), ela se opõe a qualquer tipo de ideologização da Pedagogia. Nada fácil, porém, é despertar a consciência crítica sem transformá-la, por sua vez, em doutrinação ideológica. De fato aqui não existe qualquer via régia. Em busca de uma saída, é a recuperação da tradição da crítica de ideologias que nos pode dar uma pista importante.

A experiência que poderia ser considerada paradigmática remete ao método crítico da ideologia liberal, defendido por K. Marx nas trilhas da filosofia de G. W. F. Hegel. Aí, a perspectiva crítica não nasceu da simples oposição de uma teoria a outra, como ocorria antes, e para afirmar a própria superioridade. Uma tal oposição leva apenas ao conflito insolúvel entre ideologias que insistem na prevalência de seus pressupostos fundamentadores. Em contrapartida a essa oposição ingênua, o caminho escolhido por K. Marx foi mais sofisticado. Pois, para evitar o risco de tornar-se, ele mesmo, um ideólogo, K. Marx abriu-se à lógica intrínseca à teoria dos economistas de sua época. Ao tomá-la a sério, e acompanhando o modo de argumentar de que ela se valia, ele constatou que essa teoria não chega a cumprir suas pretensões. Foi essa sua descoberta das inconsistências da teoria investigada que o levou à lógica do capital e à denúncia de seu caráter meramente ideológico, manifesto na oposição à ideia de liberdade humana como princípio organizador da sociedade capitalista. Aí, a crítica foi fundamentada no diagnóstico de falhas inscritas na teoria investigada, sem necessidade de recorrer a pressuposições a ela alheias.

$\mathrm{Na}$ verdade, K. Marx apontou o que escapa à teoria criticada. $\mathrm{O}$ fim da crítica passa, portanto, a tornar visível o lado que, embora objetivado, vê-se excluído e oculto pela ideologia liberal. O caminho de Marx revela uma 
concepção surpreendente do que a crítica deve ser: ela nasce da descoberta dos limites objetivos da conceptualização com a qual a respectiva teoria vem trabalhando.

Em vez de oferecer um chão supostamente seguro, como a defesa das ideologias promete, a crítica percorre um caminho aventuroso, fazendo descobertas imprevisíveis, pois ela não sabe de antemão para onde será levada, o que faz parecer que esse seu caminho leve à perda das certezas visadas. Se olharmos mais atentamente, porém, veremos que não é esse o efeito verificado. Ao contrário, uma convicção se fortalece à medida que prevê desde logo os raciocínios de teorias discordantes, ao passo que qualquer afirmação meramente apodítica fica desprotegida, sendo ameaçada continuamente por argumentos fortes que poderiam pô-la em xeque.

A importância desse tipo de crítica para a educação salta hoje aos olhos. A doutrinação ideológica e a ideologia da crítica a qualquer preço marcam dois extremos no debate atual da Pedagogia, criando, com isso, uma alternativa conceptual apenas destrutiva. O conflito é bem claro: é oportuno educar os jovens no sentido de integrá-los no sistema ideológico vigente, ou deve-se fazer deles críticos radicais que, sem perspectiva construtiva, vêm a perder-se numa postura meramente negadora? Escolhendo um ou outro caminho, a educação faz dos educandos ou sujeitos-súditos confiantes nas diretrizes socioculturais em vigor, ou rebeldes que fogem a qualquer responsabilidade quanto à definição de sua vida em sociedade. A tradição da crítica de ideologias como procedimento crítico-reflexivo escapa dessa falsa alternativa. Por extrair dos raciocínios da ideologia os seus próprios argumentos fundamentadores, ela mostra interdependência mútua, existente entre ambas: ela mostra que não há crítica sem tomar a posição criticada a sério.

Filosofia e Educação [RFE] - Volume 8, Número 2 - Campinas, SP Junho-Setembro de 2016 - ISSN 1984-9605 - p. 44-61 


\section{Conflitos estruturais}

Menos considerados, mas nem por isso menos importantes para a práxis educativa, são conflitos estruturais causados pela dinâmica do desenvolvimento do ambiente político-social. Como não são de seu domínio, a Pedagogia pouco se preocupa com eles, permitindo que determinem, nem sempre de modo visível, o espaço de atuação dos profissionais e das instituições de educação. A situação agrava-se pelo fato de as políticas educacionais disporem de meios restritos para alterar esse estado de coisas. Dos vários conflitos importados para o campo da educação, quero destacar apenas aqueles que me parecem ser os mais influentes, ainda que menos considerados.

A primeira linha de conflito estrutural é marcada pelo aumento da complexidade da sociedade moderna, complexidade essa que vem dificultando a orientação das pessoas no espaço social. Os fatores que contribuem para essa tendência são pouco transparentes e difíceis de manejar. Passo a descrever o cenário e, juntamente, os modos como nele se comportam os operadores.

Tem-se, de um lado, uma construção social complexa e, de outro, indivíduos necessitados de fios condutores para orientar-se no todo. Essa tensão marca o ponto de partida da descrição posta à base da teoria de sistema elaborada pelo sociólogo N. Luhmann. Sem questionar as razões que vinham contribuindo para o crescimento da complexidade social, Luhmann apontou a tensão entre a sociedade e seus membros; ele descreveu as várias estratégias escolhidas a fim de manejar essa complexidade (LUHMANN, 1973). A palavra mágica que encontramos aí é "redução de complexidade". Com essa expressão anuncia-se um amplo leque de técnicas, por nós utilizadas para vencer nossa desorientação. Pois, trate-se do olhar profissional, da inscrição de uma ideologia, da defesa de 
determinados princípios ético-morais ou da construção de uma cadeia de causalidades, todas essas estratégias diante de uma realidade em si complexa têm algo em comum: elas selecionam fatores que, isolados de seu ambiente, são usados para construir possíveis linhas de sentido. Como a lógica de um sistema de alta complexidade não nos é acessível no seu todo, tentamos manejá-la por meio da inscrição de matrizes de racionalidade. Assim, a (re)construção de um curriculum vitae, o olhar profissional - por exemplo, do jurista, do psicólogo ou do médico que se vê diante do múltiplo de fenômenos -, a elaboração do currículo de acordo com um determinado perfil profissional, todos esses exemplos tentam construir um fio condutor de sentido dentro de uma realidade complexa e, por isso mesmo, desorientadora.

Vistas sob esse ângulo, as políticas educacionais podem ser interpretadas do mesmo modo: elas buscam reduzir o múltiplo de demandas de formação por meio da implementação de determinadas opções. As múltiplas propostas de reformas pedagógicas que, às vezes incompatíveis entre si, nascem, desaparecem ou entram em conflito, não passam de reações à elevação contínua dos graus de complexidade social, reações eventualmente disfarçadas pela etiqueta da "modernização" da sociedade. A defesa dos mais diversos objetivos da formação dá prova disso. É necessário contemplar, em primeira linha, a competência social? A integração no mercado de trabalho? A exploração do potencial crítico e inovador? A flexibilidade e adaptação a demandas novas? Ou a integração nas normas sociais vigentes? Também o fato de ter ocorrido, ao longo dos últimos anos, uma diversificação espantosa de perfis profissionais revela o esforço desamparado do sistema educativo de encontrar modelos de orientação para os operadores num cenário com dinâmica própria e cada vez mais perturbadora.

Filosofia e Educação [RFE] - Volume 8, Número 2 - Campinas, SP Junho-Setembro de 2016 - ISSN 1984-9605 - p. 44-61 
Diante desse nível de complexidade, o campo pedagógico torna-se o parâmetro sensível quanto às dificuldades de encontrar uma reação unívoca e adequada à tensão descrita. Aí parece valer, sobretudo, uma lei: quanto maior a demanda por reformas, apontada pelo debate dos pedagogos, tanto maior o desamparo nas reações ao crescimento da complexidade e das demandas sociais. Se a Pedagogia não quiser sempre correr atrás dessa dinâmica social, apenas reagindo à "modernização" contínua da sociedade, ela terá de participar mais da elaboração e defesa das matrizes escolhidas para dar conta desses processos tidos como modernização.

Outro fundo de conflito estrutural que opera no espaço pedagógico tem sua origem na transformação contínua da sociedade de trabalho no que se discute hoje à base do conceito de "sociedade de saber" (Wissensgesellschaft). Trata-se de um fenômeno importante quanto à reavaliação do papel objetivo da formação no âmbito hodierno. Em parte até hoje considerada o meio por excelência para a ascensão e o reconhecimento sociais da pessoa, a formação vê sua função, anteriormente elitista, abandonada e substituída, passo a passo, por outra, a saber, sua função de condição necessária para a integração social. O conhecimento técnicocientífico virou uma das condições mais importantes para a participação do indivíduo na vida cotidiana e no processo de sociabilidade. A formação não é mais apanágio de uma elite, mas condição de sobrevivência. Se não cumprirem essa condição, as pessoas poderão sofrer exclusão social, perdendo as chances de conquistar sua autoestima.

Por mais saudada que fosse essa "massificação" ou "democratização" do acesso à formação, o fenômeno coloca o sistema da educação numa situação precária. Pois, tradicionalmente comprometida com a ideia de abrir o acesso ao mundo do trabalho e à ascensão social pela profissionalização, a organização do processo pedagógico vê-se desafiada, de repente, por 
demandas de outro tipo. Não é apenas a falta de espaço físico e sua adaptação funcional às novas diretrizes - sobretudo nas escolas e universidades - que torna a situação difícil. A função seletiva do sistema, que contradiz a imagem da sociedade de saber; a definição rígida de diretrizes curriculares que perpetua velhos modelos profissionais; o precário equipamento tecnológico nas salas de aula; a falta de formação contínua dos educadores - eis apenas algumas das contradições criadas pela transformação da sociedade em sociedade de saber. Porquanto o sistema educacional se recusa a reagir às apontadas demandas novas, os conflitos são programados, aumentando o risco de aprofundar a segregação e a exclusão sociais. Se os pedagogos não estiverem dispostos a participar ativamente da formulação dos parâmetros da sociedade de saber, os referidos conflitos continuarão sabotando seu objetivo. Não há como passar toda a responsabilidade única e exclusivamente para a política, pois as decisões políticas precisam de sua concretização e implementação no dia a dia dos processos pedagógicos, tarefa essa da qual os pedagogos não se devem esquivar.

O terceiro fundo de conflitos estruturais tem a ver com o fato de que o campo pedagógico faz parte da lógica mais ampla da sociedade liberal, uma sociedade comprometida com o espírito iluminista e os ideais de liberdade e igualdade. É óbvio que a realização desses ideais vem influenciando também a definição das diretrizes e organização do espaço pedagógico. Importa por isso lembrar rapidamente o espírito mais geral dessas políticas.

Querendo fazer da liberdade e da igualdade os princípios gerais da organização social, a política liberal recorre ao instrumentário jurídico. O Estado do direito supõe que a "juridificação" das relações sociais seja capaz de cumprir a tarefa. Garantir os princípios liberais dependeria, portanto, da submissão mais abrangente possível das relações sociais a regras jurídicas.

Filosofia e Educação [RFE] - Volume 8, Número 2 - Campinas, SP Junho-Setembro de 2016 - ISSN 1984-9605 - p. 44-61 
Acredita-se que, quanto maior for a abrangência dessa juridificação, tanto mais eficiente será a implementação dos princípios liberais. Visto desse modo, o sistema de educação não escapa dessa obsessão quando se vê solicitado a assumir o compromisso liberal. Pois, em nome da democratização da educação e de sua abertura para todos - isto é, independentemente de diferenças de origem e status sociais -, é inevitável introduzir cada vez mais regras no jogo, cujo cumprimento deveria levar a alcançar esses objetivos. Tanto o acesso ao sistema de educação quanto a organização do espaço pedagógico tornam-se, assim, alvos de regras jurídicas. Não é à toa que as instituições de ensino queixam-se do excesso de regras burocráticas, cujo manejo vem absorvendo parte cada vez maior de energia e de tempo dos profissionais. Tampouco pode surpreender que sejamos testemunhas da uniformização e da centralização das diretrizes pedagógicas. E, como se isso não bastasse, a juridificação vem penetrando também os conteúdos e procedimentos do trabalho pedagógico. O detalhamento das exigências curriculares, as regras quantificadoras da avaliação do rendimento, a unificação dos exames - no dia a dia do trabalho multiplicam-se regras jurídicas, cujo sentido pedagógico fica entretanto no escuro. Além disso, essas mesmas regras niveladoras aumentam o risco de desmotivar tanto os profissionais quanto os alunos, pois seus interesses vêm focalizados no cumprimento das regras para alcançar os objetivos predeterminados, antes que em abrir espaço para experiências inovadoras.

Esse é um conflito que também salta aos olhos: quanto maior a juridificação do espaço pedagógico em nome dos princípios liberais, tanto mais difícil será respeitar a ideia de formação como processo que faça valer os potenciais individuais dos educandos. Essa talvez seja a mais problemática consequência do espírito liberal na Pedagogia: o nivelamento das condições individuais de ensinar e de apreender é o preço a ser pago 
pela inserção excessiva de uma lógica jurídica niveladora na práxis pedagógica.

Seria possível mencionar mais exemplos de conflitos estruturais que, causados pelo ambiente no qual o espaço pedagógico se inscreve, confirmariam a decepção crescente por parte de muitos profissionais. Não que faltassem tentativas de reverter a situação de desânimo. Penso, entre outros, em modelos de reformulação da relação entre o poder público e as instituições de ensino, com o objetivo de devolver às instituições pedagógicas maior autonomia de decisão tanto sobre suas formas de organização quanto em relação à definição de seu perfil pedagógico. Penso, também, no avanço do modelo de trabalho, feito por alunos reunidos em grupos, junto à abolição de tradicionais critérios estritamente etários. Tampouco quero deixar de mencionar as tendências de reaproximar os métodos da educação formal e intramural àqueles praticados na pedagogia social. Contudo, embora haja esforços consideráveis nessa direção, eles não passam, por enquanto, de estágio meramente experimental, pouco questionando as fontes de conflito, das quais o sistema como um todo se alimenta.

\section{Considerações finais}

O diagnóstico apresentado aponta uma série de fontes de conflito que nem sempre são da responsabilidade exclusiva do sistema educativo. Todavia, a Pedagogia não se pode esquivar de levá-los em consideração nas suas reações à dinâmica de desenvolvimento - hoje chamada de modernização da sociedade. Tendo em vista esse cenário, há ainda muito a fazer, e estou certo de que poderemos contar com outras valiosas contribuições de Pedro Goergen para vencer os desafios a que a Pedagogia contemporânea precisa dar respostas.

Filosofia e Educação [RFE] - Volume 8, Número 2 - Campinas, SP Junho-Setembro de 2016 - ISSN 1984-9605 - p. 44-61 


\section{Referências}

BECK, Ulrich. Sociedade de risco. São Paulo: Editora 34, 2010.

FLICKINGER, Hans-Georg. O Estado liberal e a educação superior. In:

ULLMANN, R. (org.). Consacratio Mundi: Festschrift em Homenagem a Urbano Zilles. Porto Alegre: Edipucrs, 1998, p. 414-429.

LUHMANN, Niklas. Vertranen: ein Mechanismus der Reduktionsozialer Komplexität. [Confiança: um mecanismo de redução da complexidade social]. Stuttgart: UTB, 2000.

MARCUSE, Herbert. A ideologia da Sociedade Industrial - o homem unidimensional. 4.ed. Rio de Janeiro: Jorge Zahar, 1973.

SCHMIED-KOWARZIK, Wolfdietrich. Pedagogia dialética: de Aristóteles a Paulo Freire. São Paulo: Brasiliense, 1983.

SENNETT, Robert. A corrosão do caráter - consequênciais pessoais do trabalho no novo capitalismo. Rio de Janeiro; São Paulo: Record, 1999. 